\title{
Analysis of the Revised Trauma Score (RTS) in 200 victims of different trauma mechanisms
}

\section{Avaliação do Escore de Trauma Revisado (RTS) em 200 vítimas de trauma com mecanismos diferentes}

Bruno Durante Alvarez ${ }^{1,2}$, AcCBC-PR; Danilo Mardegam Razente 1,2, AcCBC-PR; Daniel Augusto Mauad Lacerda ${ }^{2,3}$, AcCBC-PR; Nicole Silveira Lother",2; Luiz Carlos von-Bahten", TCBC-PR; Carla Martinez Menini StahlschmidT ${ }^{4}$, ACBC-PR.

\begin{abstract}
A B S T R A C T
Objective: to analyze the epidemiological profile and mortality associated with the Revised Trauma Score (RTS) in trauma victims treated at a university hospital. Methods: we conducted a descriptive, cross-sectional study of trauma protocols (prospectively collected) from December 2013 to February 2014, including trauma victims admitted in the emergency room of the Cajuru University Hospital. We set up three groups: (G1) penetrating trauma to the abdomen and chest, (G2) blunt trauma to the abdomen and chest, and (G3) traumatic brain injury. The variables we analyzed were: gender, age, day of week, mechanism of injury, type of transportation, RTS, hospitalization time and mortality. Results: we analyzed 200 patients, with a mean age of $36.42 \pm 17.63$ years, and $73.5 \%$ were male. The mean age was significantly lower in G1 than in the other groups ( $p<0.001)$. Most $(40 \%)$ of the visits occurred on weekends and the most common pre-hospital transport service (58\%) was the SIATE (Emergency Trauma Care Integrated Service). The hospital stay was significantly higher in $G 1$ compared with the other groups ( $p<0.01$ ). Regarding mortality, there were $12 \%, 1.35 \%$ and 3.95\% of deaths in G1, G2 and G3, respectively. The median RTS among the deaths was 5.49, 7.84 and 1.16, respectively, for the three groups. Conclusion: the majority of patients were young men. RTS was effective in predicting mortality in traumatic brain injury, however failing to predict it in patients suffering from blunt and penetrating trauma.
\end{abstract}

Keywords: Traumatology. Wounds and injuries/epidemiology. Abdominal injuries. Thoracic injuries. Craniocerebral trauma. Injury Severity Score.

\section{INTRODUCTION}

$\Lambda$ nnually, 5.8 million people of all age groups and different economic strata die from unintentional injuries and violence around the world, trauma receiving the name of modern society neglected disease ${ }^{1-4}$. It is the leading cause of death in the population aged 1-44 years old, mostly men ${ }^{2,4-6}$. According to the Trauma American Committee, the estimate for 2020 is that one in ten people will die from trauma ${ }^{2}$.

Classically, mortality secondary to trauma is described as having a trimodal distribution. The first peak occurs in the first seconds to minutes following trauma due to fatal injuries. The second one occurs minutes to several hours after, resulting in serious, potentially fatal injuries if there is no intensive care. Finally, the third peak occurs several days to weeks after trauma, due to complications such as sepsis and multiple organ failure ${ }^{2,7}$.
The trauma first mortality peak is due to serious and often fatal injuries, and only prevention can be applied in its reduction. The second peak is due to potentially fatal injuries, such as subdural and epidural hematoma, hemopneumothorax, splenic rupture, liver lacerations, among others. Mortality in these cases can be reduced with early diagnosis of injuries to their rapid resolution? This is where the trauma scores should be used for a streamlined and effective approach to the trauma victim.

Many tools for the polytrauma care exist for better management of these patients, as well as to provide predictive factors of morbidity and mortality in order to generate statistical data for the establishment of preventive measures to trauma. Some of these tools are the trauma scores, which are mathematical or statistical values, quantified by numerical scores, which vary according to the severity of injuries resulting from trauma, and help the professional in the care of the

1 - Medical School, Pontifical Catholic University, Curitiba, PR, Brazil. 2 - Trauma League, Cajuru University Hospital, Curitiba, PR, Brazil. 3 - Medical School, Positivo University, Curitiba, PR, Brazil. 4 - General and Trauma Surgery, Cajuru University Hospital, Curitiba, PR, Brazil. 
injured, especially in the pre hospital environment and initial treatment in the emergency room ${ }^{5,8,9}$.

There are several trauma scores, with different levels of complexity for practical implementation. The Revised Trauma Score (RTS) is widely used by emergency services around the world. It is classified as physiological, since it takes into account parameters of the patient's vital functions. This is an improvement of Trauma Score (TS), created in 1981, but without the assessment of capillary refill and respiratory effort, difficult variables to be analyzed in practice ${ }^{10}$. RTS assesses three parameters: neurological evaluation by the Glasgow Coma Scale (GCS); hemodynamic evaluation by systolic blood pressure $(\mathrm{SBP})$; and respiratory rate $(\mathrm{RR})^{8}$. Depending on the each parameter's outcome, there is a corresponding value in the RTS scale, able to evaluate the morbidity and mortality of the polytrauma patient and, depending on the severity, indicate the recruitment of more specialized teams, to improve the approach to this type of patient.

The values of variables must be weighted and summed by the formula: RTS $=0.9368 \times \mathrm{GCS}_{\mathrm{v}}+$ $0.7326 \times \mathrm{SBP}_{\mathrm{v}}+0.2908 \times \mathrm{RR}_{\mathrm{v}}$, where $\mathrm{v}$ is the value (0-4) corresponding to the variables at the patient's admission. Thus, the RTS may vary from 0 to about 8, allowing fractions. The higher the final value, the better the prognosis, the survival probability being possibly known ${ }^{8}$ (Table 1).

On the RTS calculation formula, the greater constant multiplies the Glasgow Coma Scale, the SBP and RR being multiplied by lower constants. From this, victims of neurological trauma, whose GCS values are smaller, will have a lower final RTS result and be classified as potentially more severe. In contrast, patients with thoracic or abdominal trauma, which at first may not display changes in level of consciousness, may result in an overestimated RTS value, apparently not predicting gravity. This failure in the evaluation of such patients may not correlate well with the actual clinical situation and case seriousness, often not demanding more specialized staff, which may impair the patient's progress.

This study aims to analyze the epidemiological profile and mortality associated with the Revised Trauma Score (RTS) in trauma victims treated at a trauma reference university hospital.

\section{METHODS}

This study was approved by the Ethics in Research Committee of the Pontifical Catholic University of Paraná (number 480483 of 04.12.2013).

We prospective collected data from trauma protocols of all trauma victims seen at the Emergency Room of the Cajuru University Hospital (HUC) between December 7, 2013 and February 1, 2014 for a period of 24 hours a day including holidays. For data collection, we used the help of the Medical School undergraduates of the Cajuru University Hospital Trauma League (LATHUC). The researchers trained 35 students, accounting for a total of four hours of training, explaining the research's importance and the proper way of filling the form.

This is a descriptive, cross-sectional study of trauma protocols (prospectively collected) held in Curiti-

Table 1. RTS Parameters and survival rate.

\begin{tabular}{lccccccccc}
\hline \multicolumn{1}{c}{ 1A } & \multicolumn{4}{c}{ Parameter values } & \multicolumn{3}{c}{ 1B } & \multicolumn{3}{c}{ Survival Probability (\%) } \\
\multicolumn{1}{c}{ GCS } & v & SBP & $v$ & RR & $v$ & RTS & $\%$ & RTS & $\%$ \\
\hline $13-15$ & 4 & $>89$ & 4 & $10-29$ & 4 & 8 & 98.8 & 3 & 30.1 \\
$9-12$ & 3 & $76-89$ & 3 & $>29$ & 3 & 7 & 96.9 & 2 & 17.2 \\
$6-8$ & 2 & $50-75$ & 2 & $6-9$ & 2 & 6 & 91.9 & 1 & 7.1 \\
$4-5$ & 1 & $1-49$ & 1 & $1-5$ & 1 & 5 & 80.7 & 0 & 2.7 \\
3 & 0 & 0 & 0 & 0 & 0 & 4 & 60.5 & & \\
\hline
\end{tabular}

GCS: Glasgow coma scale, v: value, SBP: systolic blood pressure, RR: respiratory rate, RTS: revised trauma score 
ba, a city of great size of the State of Paraná. The survey took place through the data collection of 825 records of trauma patients seen in the HUC emergency room. We randomly selected the first 200 records that had the trauma mechanisms specific of the research. We divided patients into three groups according to their mechanism of injury: Group 1 - penetrating trauma to the chest and abdomen; Group 2 - blunt trauma to the chest and abdomen; and Group 3 - blunt trauma to the brain.

The group of variables consists of four parameters, trauma mechanism, Glasgow coma scale, systolic blood pressure and respiratory rate, besides epidemiological data, such as gender, age, day of the week, type of transportation, hospitalization time and patients who died.

After tabulating the results of quantitative variables, we described them by means and standard deviations or medians and quartiles. We described qualitative variables as frequencies and percentages. To compare the types of trauma (penetrating, blunt or brain) in relation to age, we used the analysis of variance (ANOVA) with one factor or the nonparametric Kruskal-Wallis test. For comparison regarding death, we used the Fisher's exact test. We considered $p$ values $<0.05$ as statistically significant. We analyzed data with the software SPSS Statistics v.20.0.

\section{RESULTS}

The study included 200 trauma victims, ranging in age from six to 91 years (mean $36.42 \pm$ 17.63), $73.5 \%$ being male. Of the total sample, we found 50 patients who suffered penetrating trauma - gunshot wounds (GW) and stabbing wounds (SW) - to the chest and abdomen, 74 patients sustaining blunt trauma to the chest and abdomen and 76 patients with brain blunt trauma. When comparing the quantitative variables between the groups with penetrating trauma $(\mathrm{G} 1)$, with blunt trauma (G2) and traumatic brain injury (G3), we noted statistically significant $(p<0.001)$ differences between $G 1$ and G2 - mean age $27.1 \pm 11.1$ years versus $38.5 \pm 15.5$, and between $\mathrm{G} 1$ and $\mathrm{G} 3-27.1 \pm 11.1$ years versus $40.6 \pm 20.7$. We did observe statistical significance ( $p=0.442$ ) between $\mathrm{G} 2$ and $\mathrm{G} 3-38.5 \pm 15.5$ years versus $40.6 \pm 20.7$ years. The male gender was the most frequent in the three groups: $\mathrm{G} 1=46(92 \%)$, $\mathrm{G} 2=54(73 \%)$ and $\mathrm{G} 3=47(61.9 \%)$.

The main type of pre-hospital transportation was the emergency room was SIATE (Emergency Trauma Care Integrated Service - 193), responsible for the transport of 116 (58\%) patients, followed by SAMU (Mobile Emergency Service - 192), responsible for for $43(21.5 \%)$, highway concessionaire, for $14(7 \%)$, direct search for $14(7 \%)$ and other means of transportation, by $13(6.5 \%)$ patients.

The most common mechanisms of trauma in each group were: G1 - GW, 31 (62\%) and SW, 19 (38\%); G2 - motorcycle accident, 24 (32.4\%), automobile accident, 20 (27\%), fall from height, ten $(13.5 \%)$, assault, six (8.1\%), fall from own, height four $(5.4 \%)$, bike accident, three $(4.1 \%)$ and running over, 2 (2,7\%); G3 - car accident, 14 (18.4\%), fall from own height, 14 (18.4\%), assault, 14 (18.4\%), running over, $13(17.1 \%)$, motorcycle accident, eight (10.5\%), fall from height, seven (9.2\%) and bike accident, six (8\%).

With regard to the day of the week, 43 $(21.5 \%)$ calls occurred on Saturday, followed by: Sunday, 37 (18.5\%), Mondays and Wednesdays, 29 (14.5\%), Thursday, 26 (13\%) Friday, 21 (10.5\%) and Tuesday, 15 (7.5\%). By separately analyzing the groups, we observed that: in G1, $13(26 \%)$ of the visits occurred on Saturday, followed by 11 (22\%) on Sunday, six (12\%) on Mondays, Wednesdays and Fridays, five $(10 \%)$ on Thursdays and three $(6 \%)$ on Tuesdays; in G2, 15 (20.3\%) of the visits occurred on Saturdays, $13(17.6 \%)$ on Mondays and Wednesdays, ten (13.5) on Thursdays and Fridays, eight (10.8\%) on Sundays and five (6.8\%) on Tuesdays; and in G3, 18 (23.7\%) of the visits occurred on Sundays, 15 (19.7\%) on Saturdays, 11 (14.5\%) on Thursdays, ten (13.2\%) on Mondays and Wednesdays, seven (9.2\%) on Tuesdays and five $(6.6 \%)$ on Fridays. 
Table 2. Distribution of the RTS parameters by groups.

\begin{tabular}{|c|c|c|c|c|c|c|}
\hline Variable & & $N(\%)$ & N (\%) & $N(\%)$ & N (\%) & $N(\%)$ \\
\hline 2A. SBP $(\mathrm{mmHg})$ & & $>89$ & $76-89$ & $50-75$ & $1-49$ & 0 \\
\hline Penetrating & G1 & 48 (96\%) & - & - & $1(2 \%)$ & $1(2 \%)$ \\
\hline Blunt & $\mathrm{G} 2$ & 74 (100\%) & - & - & - & - \\
\hline Brain & G3 & $73(95.8 \%)$ & $1(1.4 \%)$ & $2(2.8 \%)$ & - & - \\
\hline 2B. RR (irpm) & & $10-29$ & $>29$ & $6-9$ & $1-5$ & 0 \\
\hline Penetrating & G1 & 37 (74\%) & $12(24 \%)$ & - & - & $1(2 \%)$ \\
\hline Blunt & $\mathrm{G} 2$ & $57(77 \%)$ & $17(23 \%)$ & - & - & - \\
\hline Brain & G3 & $63(83 \%)$ & $13(17 \%)$ & - & - & - \\
\hline 2C. GCS & & $13-15$ & $9-12$ & $6-8$ & $4-5$ & 3 \\
\hline Penetrating & G1 & $42(84 \%)$ & $3(6 \%)$ & $1(2 \%)$ & $1(2 \%)$ & $3(6 \%)$ \\
\hline Blunt & G2 & $72(97.3 \%)$ & $1(1.35 \%)$ & $1(1.35 \%)$ & - & - \\
\hline Brain & G3 & $67(87.4 \%)$ & $3(4.2 \%)$ & $1(1.4 \%)$ & $2(2.4 \%)$ & $3(4.2 \%)$ \\
\hline
\end{tabular}

SBP: systolic blood pressure, $\mathrm{mmHg}$ : millimeters of mercury, RR: respiratory rate, irpm: respiratory incursions per minute, GCS: Glasgow coma scale.

Table 2 shows the distribution of RTS parameters in each study group.

The mean RTS value for the total sample was 7.53. In G1, the average was 7.29 and median 7.84 with $1^{\text {st }}$ and $3^{\text {rd }}$ quartile $=7.84$. In G2, the RTS average was 7.79 and median 7.84 with $1^{\text {st }}$ and $3^{\text {rd }}$ quartiles with the same value. In G3, the average was 7.44 with a median of 7.84 and $1^{\text {st }}$ and $3^{\text {rd }}$ quartile $=7.84$. We found statistically significant ( $p=0.003$ ) when comparing the medians between the groups $G 1$ and $G 2$, but not when assessing $G 1$ versus $G 3(p=0.207)$ and $G 2$ versus $G 3$ ( $p=0.052$ ).

The data regarding the length of stay are shown in Table 3, the overall average being $12.76 \pm$ 32.29 days.

Of the 200 evaluated patients, ten (5\%) died, six as a result of penetrating trauma, three due to brain trauma and one victim by blunt trauma. Mortality and comparison between groups are presented in Table 4.

All $\mathrm{G} 1$ deaths were male and the median age was 25.5 years, with the $1^{\text {st }}$ quartile 22.25 , and $3^{\text {rd }}$, 31. The Glasgow Coma Scale presented a median of six, with $1^{\text {st }}$ quartile three, and $3^{\text {rd }}, 13.5$. The median length of stay was 0.5 days, with $1^{\text {st }}$ quartile in zero and $3^{\text {rd }}$ quartile of 2.5 days. In $\mathrm{G} 2$, there was one death of a 78 year old woman, GCS 15, RTS 7.84 and two days of hospitalization. In G3, two (66.6\%) were male, the median age was 81 years, with the $1^{\text {st }}$ quartile 64 and $3^{\text {rd, }} 82$; median GCS was three, with $1^{\text {st }}$ quartile 3 and $3^{\text {rd }}$ quartile, seven; for RTS the median was 1.16 , with $1^{\text {st }}$ quartile 0.58 and $3^{\text {rd }}, 2.62$; and a median hospitalization time of six days, with $1^{\text {st }}$ quartile six and $3^{\text {rd }}$ quartile 12.

Table 3. Distribution and comparison by length of hospital stay.

\begin{tabular}{lcccccc}
\hline Group & Median & $1^{\text {st }}$ quartile & $3^{\text {rd }}$ quartile & Range & Comparison & $p$ \\
\hline G1 & 5 & 3 & 7 & $0-200$ & G1xG2 & $<0.001$ \\
G2 & 0 & 0 & 1 & $0-56$ & G1xG3 & $<0.001$ \\
G3 & 1 & 0 & 3 & $0-140$ & G2xG3 & 0.005 \\
\hline
\end{tabular}


Table 4. Mortality and RTS values.

\begin{tabular}{lccccccc}
\hline Group & Deaths $(\mathrm{n})$ & $\begin{array}{c}\text { Mortality } \\
\text { rate }\end{array}$ & $\begin{array}{c}\text { Median } \\
\text { RTS }\end{array}$ & 1st $^{\text {quartile }}$ & $3^{\text {rd }}$ quartile & Comparison & $\mathrm{p}$ \\
\hline $\mathrm{G} 1$ & 6 & $12 \%$ & 5.49 & 2.44 & 7.38 & $\mathrm{P} \times \mathrm{C}$ & 0.017 \\
$\mathrm{G} 2$ & 1 & $1.35 \%$ & 7.84 & - & - & $\mathrm{P} \times \mathrm{Cr}$ & 0.154 \\
$\mathrm{G} 3$ & 3 & $3.95 \%$ & 1.16 & 0.58 & 2.62 & $\mathrm{C} \times \mathrm{Cr}$ & 0.620 \\
\hline
\end{tabular}

\section{DISCUSSION}

One of the problems of the trauma victims approach is that the profile of the people cared differ as to the nature and severity of injuries. The heterogeneity and difficulty in adjusting these variations have stimulated scientific research ${ }^{8}$. In the present study there was a predominance of injuries in males (73.5\% of the sample), in the age range considered economically active, ie young adults, as observed in the literature ${ }^{2,4-6,8,11}$. Penetrating injuries were the ones affecting younger patients, with a mean age of 27.1 years. The highest overall prevalence of injuries occurred on weekends, $40 \%$ of cases.

Regarding the type of transportation to the emergency room, there was a predominance of SIATE - 193 - in all groups, and SAMU - 192 - in blunt and head injuries, $22 \%$ of patients suffering from penetrating wounds having been admitted after arriving through direct search, the second most prevalent type of transportation in the group.

The most prevalent mechanism in the penetrating trauma group was gunshot wound, while in blunt trauma and brain injury groups it was accidents caused by motor vehicles. According to studies by the National Department of Highways (DNER), the average cost per injured person is US\$13,360.00, this value comprising medical expenses, property damage (vehicles and highways) and the victim's loss of income during the period of inactivity ${ }^{16}$. This confirms the important role of trauma prevention in improving the economy and reducing public spending, which has been shown by several studies ${ }^{11-13}$.

Regarding RTS variables, we found that patients who suffered penetrating and blunt trauma presented, within the physiological parameters, with lower values of respiratory rate, while the systolic blood pressure values did not show significant variations. On the other hand, patients suffering from blunt injury had higher Glasgow Coma Scale values compared with the other groups. RTS values were higher among victims of blunt injury compared with victims of penetrating injury. However, when analyzing the power in predicting mortality, the three groups had similar RTS mean values.

The length of stay proved to be significantly different when comparing the three groups. The victims of penetrating trauma required more in-hospital period, becoming more costly cases to the public health system, a fact corroborated by the literature, showing that individuals victims of gunshot wounds (penetrating) have an average of 7.7 days of hospitalization, with an average cost of US\$ 692.95 to the hospital ${ }^{4}$. Another problem related to long hospital stay of trauma patients is that they contribute to overcrowding, since the lack of beds is a common health problem in the Brazilian system ${ }^{4}$.

Most patients were admitted with RTS values above seven, predicting good chance of survival. Even with average RTS values similar to other groups, victims of penetrating wounds had a mortality of $12 \%$. Among the cases of blunt trauma, mortality was $1.35 \%$, and in victims of traumatic brain injury, $3.95 \%$. We can therefore see that even being a universally accepted trauma score, RTS is faulty when analyzing patients in groups individualized by trauma mechanism, since it does not account for this variable.

The deficiency observed in the RTS computation between groups can be explained by the fact that the variable Glasgow Coma Scale (GCS) displays 
the highest constant in the score calculation. In addition, patients suffering from brain trauma more often enter the emergency room with lower minor GCS values due to local injury, while in patients with trauma to the chest and abdomen (penetrating and blunt) the level of awareness may be maintained during initial evaluation. Thus, the hypothesis arises that the variable "mechanism of injury" is an important predictive factor of mortality, future studies being needed.

When comparing only patients who died, we found statistical significance: while in G2 the victim had a RTS median value of 7.84 (98.8\% survival probability), in G1 and G3 the median values were 5.49 (60.5\% to $80.7 \%$ probability of survival) and 1.16 (7\% survival probability), respectively.

In conclusion, RTS was effective in predicting the sample overall mortality, the majority of cases displaying RTS above seven, which indicates a high probability of survival. However, when compared groups, RTS was more effective in analyzing the survival rate in patients suffering from traumatic brain injury than doing so for patients with penetrating and blunt trauma to the chest and abdomen.

\title{
R E S U M O
}

\begin{abstract}
Objetivo: analisar o perfil epidemiológico e a mortalidade associada ao escore de trauma revisado (RTS) em vítimas de trauma atendidas em um hospital universitário. Métodos: estudo transversal descritivo de protocolos de trauma (coletados prospectivamente) de dezembro de 2013 a fevereiro de 2014, incluindo vítimas de trauma admitidas na sala de emergência do Hospital Universitário Cajuru. Três grupos foram criados: (G1) trauma penetrante em abdome e tórax, (G2) trauma contuso em abdome e tórax, e (G3) trauma cranioencefálico. As variáveis analisadas foram: sexo, idade, dia da semana, mecanismo de trauma, tipo de transporte, RTS, tempo de internamento e mortalidade. Resultados: analisou-se 200 pacientes, com média de idade de 36,42 \pm 17,63 anos, sendo 73,5\% do sexo masculino. A média de idade no $\mathrm{G} 1$ foi significativamente menor do que nos demais grupos $(p<0,001)$. A maioria $(40 \%)$ dos atendimentos ocorreu nos finais de semana e o serviço de transporte pré-hospitalar mais frequente (58\%) foi o SIATE (Serviço Integrado de Atendimento ao Trauma em Emergência). O tempo de internamento foi significativamente maior no $\mathrm{G1}$, em comparação aos demais grupos $(p<0,01)$. Quanto à mortalidade, houve $12 \%, 1,35 \%$ e 3,95\% de óbitos nos grupos G1, G2 e G3, respectivamente. A mediana do RTS entre os óbitos foi 5,49, 7,84 e 1,16, respectivamente, para os três grupos. Conclusão: a maioria dos pacientes eram homens jovens. O RTS mostrou-se efetivo na predição de mortalidade no trauma cranioencefálico, entretanto falhou ao analisar pacientes vítimas de trauma contuso e penetrante.
\end{abstract}

Descritores: Traumatologia. Traumatismos/epidemiologia. Traumatismos abdominais. Traumatismos torácicos. Traumatismos craniocerebrais. Escala de Gravidade do Ferimento.

\section{REFERENCES}

1. Sociedade Brasileira de Atendimento Integrado ao Traumatizado [Internet]. São Paulo: SBAIT; c19822015 [cited 15 Aug 2015]. Available from: http:// www.sbait.org.br/

2. American College of Surgeons ATLS. Advanced Trauma Life Support: Student Course Manual. 9. ed. Chicago: American College of Surgeons; 2012.

3. Von Bahten LC, Alcantra EM, Pimenta APP, Dallagnol JC, Yoshizumi KO DM, Dresch MF. O impacto econômico do trauma em um hospital universitário. Rev Col Bras Cir. 2003;30(3):224-9.

4. Broska Jr CA, Folchini AB, Ruediger RR. Estudo comparativo entre o trauma em idosos e não idosos atendido em um Hospital Universitário de Curitiba. Rev Col Bras Cir. 2013;40(4):281-6.

5. Wilson JL, Herbella FAM, Takassi GF, Moreno DG,
Tineli AC. Lesões fatais em trauma numa grande metrópole brasileira: um estudo de autópsias. Rev Col Bras Cir. 2011;38(2):122-6.

6. Gunst M, Ghaemmaghami V, Gruszecki A, Urban J, Frankel H, Shafi S. Changing epidemiology of trauma deaths leads to a bimodal distribution. Proc (Bayl Univ Med Cent). 2010;23(4):349-54.

7. Champion HR, Sacco WJ, Copes WS, Gann DS, Gennarelli TA, Flanagan ME. A revision of the Trauma Score. J Trauma. 1989;29(5):623-9.

8. Domingues CA, Nogueira LS, Settervall CHC, Souza RMC. Desempenho dos ajustes do Trauma and Injury Severity Score (TRISS): revisão integrativa. Rev Esc Enferm USP. 2015;49(Esp):138-46.

9. Gabbe BJ, Cameron PA, Finch CF. Is the revised trauma score still useful? ANZ J Surg. 2003;7(11):944-8.

10. Paixão LMMM, Gontijo ED, Drumond EF, Friche AAL, Caiaffa WT. Acidentes de trânsito em Belo 
Horizonte: o que revelam três diferentes fontes de informações, 2008 a 2010. Rev Bras Epidemiol. 2015;18(1):108-22.

11. Carreiro PRL, Drumond DAF, Starling SV, Moritz M, Ladeira RM. Implantação de um registro de trauma em um hospital público brasileiro: os primeiros 1000 pacientes. Rev Col Bras Cir. 2014;41(4):251-5.

12. Dutra VC, Caregnato RCA, Figueiredo MRB, Schneider DS. Traumatismos craniocerebrais em motociclistas: relação do uso de capacete e gravidade. Acta Paul Enferm. 2014;27(5):485-91.
Received in: 18/05/2016

Accepted for publication: 18/08/2016 Conflict of interest: none.

Source of funding: none.

\section{Mailing address:}

Bruno Durante Alvarez

E-mail: brunoalvarez@outlook.com 